\title{
RNA Quadruplexes
}

\section{Kangkan Halder and Jörg S. Hartig}

Department of Chemistry, University of Konstanz, Universitätsstrasse 10,

D-78457 Konstanz, Germany

<joerg.hartig@uni-konstanz.de>

\section{ABSTRACT}

1. INTRODUCTION TO RNA QUADRUPLEXES 126

2. THERMODYNAMIC STABILITY 127

2.1. Role of Cations 127

2.2. Role of Loop Size and Composition 129

2.3. Comparison between DNA and RNA Quadruplexes 129

3. CONFORMATIONAL VARIATIONS 130

4. BIOLOGICAL FUNCTION 130

4.1. RNA Quadruplexes as Translation Inhibitors 132

4.2. RNA Quadruplexes in Post-Transcriptional Regulation 134

4.3. Telomeric RNA 134

4.4. RNA Quadruplex-Interacting Proteins $\quad 135$

5. CONCLUSIONS 135

ACKNOWLEDGMENT 136

ABBREVIATIONS 136

REFERENCES 137

ABSTRACT: Opposed to DNA quadruplex sequences, RNA quadruplexes are still less well characterized. On the other hand, RNA quadruplexes are found to be at least as stable as their DNA counterparts. They show the same dependence on metal ions but seem to be much more restricted with respect to the adopted conformations. Other than DNA, which is mostly found to be double-stranded inside cells, RNAs are produced during transcription without its complementary sequence. The absence of a second 
strand that is able to hybridize and form a duplex makes the folding of RNA quadruplexes a likely event of intramolecular structure formation. Consequently, the formation of RNA quadruplexes in cellular RNAs has recently been suggested and the study of their influence and potential roles in cellular processes has just started. Here we give an overview of the RNA quadruplex field, summarizing issues such as structures, stabilities, and anticipated roles of these interesting four-stranded, guanosine-rich sequences.

KEYWORDS: gene expression - G-quadruplex - G-quartet - guanosine potassium - transcription - translation - telomere

\section{INTRODUCTION TO RNA QUADRUPLEXES}

As early as 1962, it was proposed that four guanine monophosphate dianions can assemble coplanarly stabilized by two hydrogen bonds per base [1], later termed as G-tetrad or G-quartet (Figure 1A). These tetramolecular arrangements then prefer to consecutively stack on top of each other due to strong unpolar attractions resulting in a four-stranded helical conformation known as the G-quadruplex motif (Figure 1B). Similar multi-stranded arrangements were proposed for poly-guanylic acid sequences stabilized by $\mathrm{Na}^{+}$ions, shortly thereafter in 1963 [2].

Though initially studied for structural information, in the last two decades these higher order nucleic acid conformations have been proposed to be involved in various biological functions such as gene regulation $[3,4]$, nucleosome positioning $[5,6]$, recombination [7], and genomic maintenance [8]. However, studies proving their in vivo existence are limited $[9,10]$. This is

A

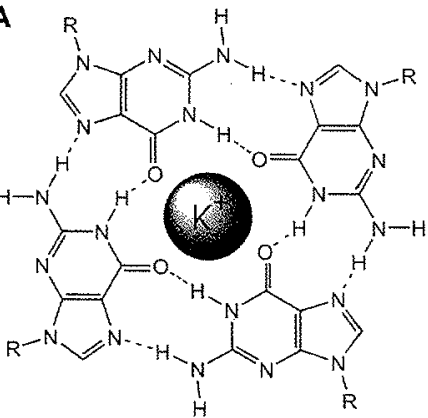

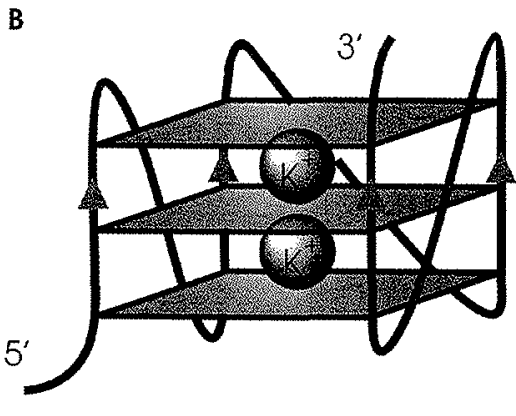

B

Figure 1. (A) Schematic of a G-tetrad. Hoogsteen hydrogen bonding is shown in dotted lines. (B) Cartoon of a parallel intramolecular G-quadruplex motif. The arrows indicate the 5 ' to 3 ' oligonucleotide orientation. 
primarily due to the general acceptance that duplex DNA is the thermodynamically favorable state compared to the G-quadruplex motif in the presence of a complementary strand [11,12]. The single-stranded $3^{\prime}$-overhang of the telomeric repeat, which has been shown to adopt G-quadruplex structures in vitro [13], is the most studied G-quadruplex-forming sequence.

However, it has been shown that 'capping' of the telomere end involves structures like the 't-loop' [14] as well as protein-ssDNA interactions [15] which are compromised by $G$-quadruplex formation. On the other hand, single stranded mRNA sequences harboring guanosine-rich stretches could also potentially form four-stranded structures in vivo. Proteins capable of inducing or stabilizing. DNA and RNA G-quadruplexes have been described, which in turn may have functional relevance [16]. Here we primarily discuss RNA quadruplexes and their biological significance.

\section{THERMODYNAMIC STABILITY}

\subsection{Role of Cations}

The G-quartet conformation results in four carbonyl oxygen atoms clustered towards the center (Figure 1A) which necessitates a cation to effectively neutralize the partial negative charge [17]. The size of the inner cavity is an important factor to match with the ionic radii of the cation for suitable coordination interaction. The $\mathrm{K}^{+}$ion (ionic radius of $1.33 \AA$ ) is the most suitable and studied cation. Interestingly, it is also the monovalent cation with the highest intercellular concentration. However, a wide range of cations has been tested for its role in DNA G-quadruplex formation and stability. The general pattern of stability mediated by monovalent and divalent cations has been found as $\mathrm{K}^{+} \gg \mathrm{Na}^{+} \geq \mathrm{Rb}^{+}>\mathrm{Cs}^{+} \geq \mathrm{Li}^{+}[18,19]$ and $\mathrm{Sr}^{2+} \gg \mathrm{Ba}^{2+}>\mathrm{Ca}^{2+}>\mathrm{Mg}^{2+}>\mathrm{Mn}^{2+}>\mathrm{Co}^{2+}>\mathrm{Zn}^{2+}[20-22]$, respectively. Though a similar thermodynamic hierarchy is expected for RNA quadruplexes, only a few studies are known (Table 1) and further studies are required to substantiate metal ion dependency.

The high affinity of $\mathrm{K}^{+}$ions in RNA quadruplexes is exemplified by 10 to $30^{\circ} \mathrm{C}$ higher increases in melting temperature $\left(T_{1 / 2}\right)$ compared with $\mathrm{Na}^{+}$ions under similar conditions [23-25]. The sensitivity towards the cation concentration is well documented for DNA quadruplexes and similar results were found for RNA quadruplexes too, though limited to a few studies $[23,25]$. A gradual increase of the $\mathrm{K}^{+}$ion concentration was found to consistently elevate the melting temperatures $\left(T_{1 / 2}\right)$. At physiological concentrations as high as $150 \mathrm{mM} \mathrm{K}{ }^{+}$some quadruplex motifs are resistant to denaturing even at $90^{\circ} \mathrm{C}$. It is also worth mentioning that supplementing 
Table 1. Melting temperatures of RNA G-quadruplexes.

\begin{tabular}{|c|c|c|c|c|c|c|}
\hline \multirow[b]{2}{*}{ G-quadruplex sequence $\left(5^{\prime} \rightarrow 3^{f}\right)^{a}$} & \multicolumn{3}{|c|}{ RNA } & \multicolumn{3}{|c|}{$\mathrm{DNA}^{i}$} \\
\hline & $T_{1 / 2}\left({ }^{\circ} \mathrm{C}\right)$ & Salt (mM) & Ref. & $T_{1 / 2}\left({ }^{\circ} \mathrm{C}\right)^{b}$ & Salt (mM) & Ref \\
\hline UAGGGUUAGGGU & $63.3 ; 38.8,41$ & $\mathrm{~K}^{+}(70) ; \mathrm{Na}^{+}(70,100)$ & {$[23],[39]$} & & & \\
\hline $\mathrm{U}_{n} \mathrm{GGGU}_{n}(\mathrm{n}=1-3)$ & $50-89$ & $\mathrm{Na}^{+}(110)$ & {$[38],[42]$} & & & \\
\hline UGGAGGU & $>90$ & $\mathrm{~K}^{+}(150)$ & {$[41]$} & & & \\
\hline$(\mathrm{GGGU})_{3} \mathrm{GGG}$ & $>90 ; 73$ & $\mathrm{~K}^{\div}(10,100) ; \mathrm{Na}^{+}(100)$ & {$[29],[24]$} & & $\mathrm{K}^{+}(100) ; \mathrm{Na}^{+}(100)$ & [24] \\
\hline$(\mathrm{GGGUU})_{3} \mathrm{GGG}$ & 73 & $K^{+}(10)$ & [29] & & & \\
\hline (GGGUUU) ${ }_{3}$ GGG & 61 & $\mathrm{~K}^{+}(10)$ & [29] & & & \\
\hline$(G G G \cup U A)_{3} G G G$ & $73 ; 42$ & $\mathrm{~K}^{+}(100) ; \mathrm{Na}^{+}(100)$ & {$[24]$} & $65 ; 47$ & $\mathrm{~K}^{+}(100) ; \mathrm{Na}^{+}(100)$ & [24] \\
\hline $\mathrm{A}(\mathrm{GGGUUA})_{3} \mathrm{GGGUU}$ & 76 & $\mathrm{~K}^{+}(100)$ & {$[26]$} & 63 & $\mathrm{~K} \div(100)$ & \\
\hline (GGGGUUUU) ${ }_{3} \mathrm{GGG}$ & $>90 ; 60$ & $\mathrm{~K}^{+}(100) ; \mathrm{Na}^{+}(100)$ & {$[24]$} & $>90 ; 65$ & $\mathrm{~K}^{+}(100) ; \mathrm{Na}^{+}(100)$ & [24] \\
\hline$(\mathrm{GGU})_{3} \mathrm{GG}$ & $63 ; 31$ & $\mathrm{~K}^{+}(100) ; \mathrm{Na}^{+}(100)$ & {$[24]$} & $58 ;<20$ & $\mathrm{~K}^{+}(100) ; \mathrm{Na}^{+}(100)$ & [24] \\
\hline GGUUGGUGUGGUUGG & $54 ;<20$ & $\mathrm{~K}^{+}(100) ; \mathrm{Na}^{+}(100)$ & {$[24]$} & $52 ;<20$ & $\mathrm{~K}^{+}(100) ; \mathrm{Na}^{+}(100)$ & [24] \\
\hline GGGUGGGAAGGAGGGUGGGCAUGGG & $>90$ & $\mathrm{~K}^{+}(100)$ & {$[30]$} & & & \\
\hline GGGUUGGGAAGGAGGGUUGGGAUGGG & 78.7 & $K^{+}(100)$ & {$[30]$} & & & \\
\hline GGUGGAAGGAGGUGGUUCAUGGG & 56.5 & $\mathrm{~K}^{+}(100)$ & {$[30]$} & & & \\
\hline GGUUGGAAGGAGGUUGGUCATGGG & 53.7 & $\mathrm{~K}^{+}(100)$ & {$[30]$} & & & \\
\hline GGGUGGGGGGGGCGGGGGAGGCCGGGG & 79 & $K^{+}(25)$ & {$[52]$} & & & \\
\hline GGGAGGGGCGGGUCUGGG & & & {$[25]$} & & & \\
\hline UGUGGGGAGGGGCGGGGUCUGGGG & 80 & $K^{+}(10)$ & {$[25]$} & & & \\
\hline UGUGGGAGGGGCGGGUCUGGG & 74 & $\mathrm{~K}^{+}(10)$ & {$[25]$} & & & \\
\hline UGUGGUAGGGUCGGUUCUGGU & 45 & $\mathrm{~K}^{+}(100)$ & {$[25]$} & & & \\
\hline
\end{tabular}

${ }^{a}$ DNA oligodeoxynucleotides have $T$ instead of $U$ in the G-quadruplex forming sequence.

${ }^{b}$ Melting temperatures with most similar conditions are reported. The table is not exhaustive. 
the buffer with osmolytes (e.g., ethylene glycol), which mimic physiologic conditions better than buffer alone, further increase $T_{1 / 2}$, showing that supramolecularly crowded environments have stabilizing effects on RNA quadruplex formation [26]. Taken together, formation of an RNA quadruplex structure is very likely under physiological conditions unless other factors that competitively stabilize the unstructured conformation are present.

\subsection{Role of Loop Size and Composition}

The number and composition of nucleotides in the three loops of intramolecular DNA G-quadruplexes are crucial factors for the preferred topology as well as stability $[27,28]$, however, a systematic study is lacking for RNA quadruplexes. We recently determined the melting temperatures $\left(T_{1 / 2}\right)$ of various RNA quadruplexes with different loop sizes and composition $[24,29,30]$. It shows that the thermodynamic stability is inversely correlated with the loop size, a finding that matches the behavior of similar DNA sequences (Table 1). Moreover, stacking of three G-tetrads is found to be considerably more stable than two G-tetrads, which is expected due to additional stacking interactions in the former conformation $[24,30]$.

\subsection{Comparison between DNA and RNA Quadruplexes}

It is interesting to compare stability parameters between DNA and RNA quadruplexes especially since various genomic G-quadruplex forming regions are transcribed. In general, slightly increased $T_{1 / 2}$ values were found for RNA quadruplexes compared to the corresponding DNA counterparts (Table 1). The disparity is believed to arise from better stacking of G-tetrads and the 2'-OH group is able to form additional intramolecular hydrogen bonds in RNA quadruplexes [31]. Moreover, the stability could also result from higher-order scaffolding of RNA quadruplexes [32-34]. Recently, the hydration state has also been implicated in the determination of thermodynamics of DNA quadruplex formation [35]. The formation of the compact structure was found to be accompanied with release of water molecules [36,37] and a similar role is expected in RNA quadruplexes, though to a different extent. Along these lines $6.0 \pm 0.5$ water molecules were found to be liberated during RNA quadruplex formation of $r\left[A(G G G U U A)_{3}\right.$ GGGUU] while only $4.0 \pm 0.4$ water molecules were released during the corresponding DNA quadruplex formation [26]. 


\section{CONFORMATIONAL VARIATIONS}

Although there are only few high resolution structures available for RNA quadruplexes (Table 2), they are invariably found to adopt a parallel conformation [23,34,38-42] (Table 3). This is an interesting finding since the DNA counterparts can adopt several different topologies. The reason is believed to be due to the stronger preference of an anti conformation of the glycosidic bond in ribonucleotides $[43,44]$. While in DNA quadruplexes containing antiparallel strand orientations at least some of the glycosidic bonds need to adopt syn conformations, the all-parallel-oriented, so called propeller conformation adopted by RNA quadruplexes, only allows anti orientations of ribose and guanine nucleobases. For example, the solution structure reported for the human telomeric RNA sequence r[(UAGG$\left.\mathrm{G}(\mathrm{UUAGGG})_{3}\right]$ in the presence of $\mathrm{K}^{+}$has been shown to form this allparallel conformation [23]. This is in contrast to its DNA counterpart, d[AGGG(TTAGGG) 3 ], which has been reported to form parallel as well as antiparallel conformations in both $\mathrm{Na}^{+}$and $\mathrm{K}^{+}$solutions [45-48]. The 12 nucleotide smaller fragment, r(UAGGGUUAGGGU), also formed a parallel conformation as a dimer in the presence of $\mathrm{K}^{+}[23]$ and $\mathrm{Na}^{+}[39]$ ions. Considering other RNA quadruplex sequences (Table 3 ), the parallel conformation seems universal for RNA quadruplexes. Importantly, this fact could be exploited for differential targeting of DNA and RNA quadruplexes for potential therapeutic purposes.

\section{BIOLOGICAL FUNCTION}

The biophysical studies documenting thermodynamic stability of RNA quadruplexes near physiological conditions point to the existence of such structures inside cells. Though partially less stable than RNA quadruplexes, as early as 1994 the telomeric DNA quadruplex was found to interfere with

Table 2. Structure of RNA G-quadruplexes.

\begin{tabular}{llll}
\hline PDB Id & G-quadruplex sequence $\left(5^{\prime} \rightarrow 3^{\prime}\right)$ & Method & Ref. \\
\hline 2KBP & UAGGGUUAGGGU & NMR & {$[23]$} \\
2GRB & $\left(\mathrm{U}^{33}\right)$ GIGGU & X-Ray & {$[32]$} \\
IMY9 & GGAGGUUUUGGAGG & NMR & {$[34]$} \\
IJ8G & UGGGGU & X-Ray & {$[40]$} \\
IRAU & UGGGGU & NMR & {$[68]$} \\
2RQJ & GGAGGAGGAGGA & NMR & {$[69]$} \\
\hline
\end{tabular}


Table 3. Conformations adopted by RNA quadruplexes.

\begin{tabular}{|c|c|c|c|c|}
\hline & $G$-quadruplex sequence $\left(5^{\prime} \rightarrow 3^{\prime}\right)$ & Conformation & Salt (mM) & Ref. \\
\hline \multirow[t]{9}{*}{ Intramolecular } & UAGGGUUAGGGUUAGGGUUAGGG & all-paralle! $^{a}$ & $\mathrm{~K}^{+}(70)$ & {$[23]$} \\
\hline & UUAGGGUUAGGGUUAGGGUUAGGG & all-parallel & $\mathrm{Na}^{+}(100)$ & {$[39]$} \\
\hline & GGGUGGGAAGGAGGGUGGGCAUGGG & all parallel & $K^{+}(100)$ & {$[30]$} \\
\hline & GGGUUGGGAAGGAGGGUUGGGAUGGG & all-parallel & $\mathrm{K}^{+}(100)$ & {$[30]$} \\
\hline & GGUGGAAGGAGGUGGUUCAUGGG & all-parallel & $\mathrm{K}^{+}(100)$ & {$[30]$} \\
\hline & GGUUGGAAGGAGGUUGGUCATGGG & all-parallel & $\mathrm{K}^{+}(100)$ & {$[30]$} \\
\hline & $\mathrm{GGGU}_{n} \mathrm{GGGU}_{\mathrm{n}} \mathrm{GGGU}_{\mathrm{n}} \mathrm{GGG}(\mathrm{n}=1-3)$ & all-parallel & $\mathrm{K}^{+}(10)$ & {$[29]$} \\
\hline & GGGUGGGGGGGGCGGGGGAGGCCGGGG & all-parallel & $\mathrm{K}^{+}(25)$ & [52] \\
\hline & $($ UUAGGG) 96 & all-parallel & $\mathrm{K}^{+}(100)$ & {$[62]$} \\
\hline \multirow[t]{3}{*}{ Intermolecular } & UAGGGUUAGGGU & all-parallel & $\mathrm{K}^{+}(70) ; \mathrm{Na}^{+}(100)$ & {$[23] ;[39]$} \\
\hline & UGGGGU & all-parallel & $\begin{array}{l}\mathrm{Sr}^{2+}(40), \mathrm{Ca}^{2+}(20) \\
\mathrm{Li}^{+}(80), \mathrm{Mg}^{2+}(20) \\
\mathrm{Na}^{+}(40)\end{array}$ & {$[40]$} \\
\hline & UGGAGGU & all-parallel & $\mathrm{K}^{+}(150)$ & {$[41]$} \\
\hline
\end{tabular}

${ }^{a}$ As determined by $\mathrm{CD}$ spectroscopy (approx. at $\sim 265 \mathrm{~nm}$ positive and $240 \mathrm{~nm}$ negative peak) 
telomerase recognition and activity (telomeric repeat amplification protocol, TRAP assay) [49] and since then the method has been extensively used to evaluate quadruplex formation and stability. A similar scenario could be easily perceived for RNA quadruplexes in mRNAs too; wherein these compact structures would hinder the assembly or scanning of proteins associated with the translation initiation complex. Alternatively, it is also possible that such distinct nucleic acid structures act as recognition sites for specific proteins in regulatory processes.

\subsection{RNA Quadruplexes as Translation Inhibitors}

The unusual stability of these RNA structures could possibly interfere with the ribosomal assembly and activity, especially when found in 5'-untranslated regions (5'-UTRs, see Figure 2A). Computational searches found a high prevalence of sequences potentially forming RNA quadruplexes in

A.

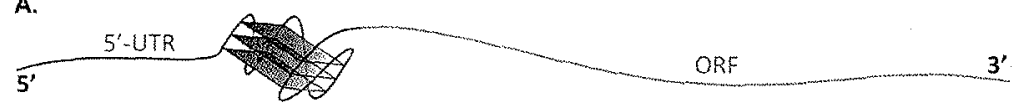

B.

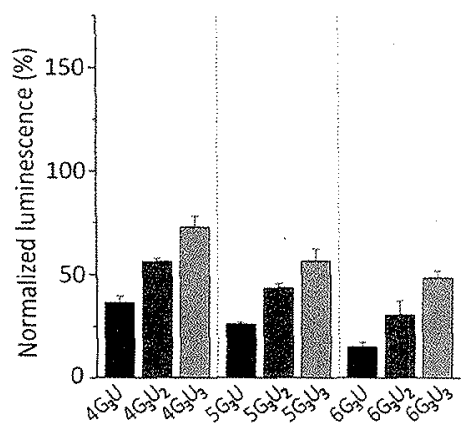

c.

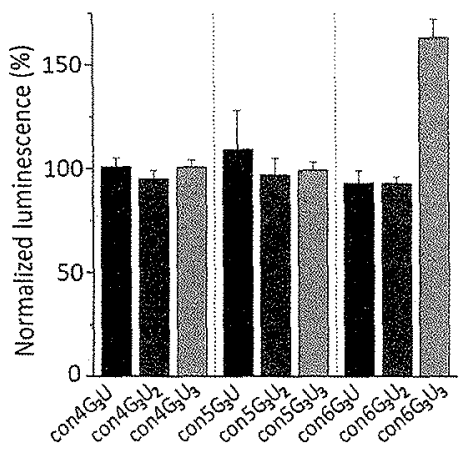

Figure 2. (A) Schematic representation of a parallel RNA quadruplex in a 5'-UTR of a mRNA. (B) Normalized luciferase luminescence of various 5'-UTRs containing RNA quadruplexes and $(C)$ respective control sequences. The normalized luminescence of the wild-type luciferase (not shown) is set to $100 \%$ in the above scale. The prefix 4,5 or 6 in the 'plasmid construct name' represents the total number of GGG repeats in the RNA quadruplex interspersed by 1,2 or $3(\mathrm{y})$ U's. A further prefix of 'con' abbreviates the control sequences, wherein three $G$ positions were mutated to $\mathrm{U}$, such that quadruplex structure formation is compromized [29]. 
5'-UTRs of human genes $[25,29,50,51]$. This has prompted us and other groups to investigate the influence of such structures at these positions in detail. Balasubramanian's group first reported that the presence of an RNA quadruplex in the 5'-UTR of the NRAS mRNA exhibits an inhibitory effect on translation [50]. The effect was found to be more pronounced when the quadruplex was located near the 5'-end [25], though in vitro transcription and in vitro translation methods were used to study the influence on gene expression. Shortly thereafter, an in vivo functional characterization of an RNA quadruplex in the $Z I C-1$ mRNA also concluded a similar inhibitory effect on translation [52]. The above studies were limited to two specific RNA quadruplex motifs. We took a more systematic approach and incorporated an array of G-quadruplexes with varying loop sizes ( 1 to 3 nucleotides) and GGG-repeats ( 4 to 6 repeats) along with $G$ to $U$ mutant sequences as structural controls that should disrupt quadruplex formation [29].

The study was initiated in order to investigate whether there is any correlation of the thermodynamic stability of an RNA quadruplex and its effect on gene expression. We found that a gradual increase of loop sizes from 1 to 3 uridines in $4 \mathrm{G}_{3} \mathrm{U}_{y}$ RNA quadruplexes is accompanied by thermodynamic destabilization (Table 1). Interestingly, when incorporated into mRNAs the activity of gene expression increased in this series (Figure 2A). In other words, the more the RNA quadruplex is thermodynamically stable, the higher is the level of repression of gene expression. Analogous results were found for the series $5 \mathrm{G}_{3} \mathrm{U}_{\mathrm{y}}$ and $6 \mathrm{G}_{3} \mathrm{U}_{\mathrm{y}}$. Additionally, it was found that quadruplexes containing more than the minimal required four G-rich repeats (such as $5 \mathrm{G}_{3} \mathrm{U}$ and $6 \mathrm{G}_{3} \mathrm{U}$ ) are thermodynamically more stable than the corresponding four-repeat sequence $\left(4 \mathrm{G}_{3} \mathrm{U}\right)$. Accordingly, $6 \mathrm{G}_{3} \mathrm{U}$ incorporated into $m R N A s$ displayed less gene expression compared to $5 \mathrm{G}_{3} \mathrm{U}$ and $4 G_{3} U$. The specificity and correlation of expression with quadruplex formation was confirmed when a minimal change of three $G$ to $U$ mutations for each respective quadruplex fully recovered gene expression (Figure 2B). Apart from these designed, very symmetrical quadruplexes, we also incorporated naturally occurring 5'-UTR RNA quadruplexes with different loop compositions and lengths into our constructs, and the observed expression matched those of similarly composed synthetic constructs. This result indicates that the level of translation inhibition is proportional to structure stability and can be tuned with changes in loop composition and length. In a next step we quantified the levels of reporter gene mRNA for various constructs in order to decipher whether the inhibition of gene expression takes place at the transcriptional or posttranscriptional/translational level. We found that the incorporation of quadruplexes into the 5'-UTR of the reporter genes has no influence on mRNA abundance, ruling out a potential effect on transcription or mRNA stability and indicating that the inhibition of expression takes place at the level of translation initiation. We also found 
that the insertion position of the G-quadruplex sequence within the 5'UTR has an effect on the level of suppression [29], a finding that has been reported before but with slightly different position dependencies [25]. However, further studies are necessary to decipher the exact mechanism of how quadruplex formation affects gene expression on the post-transcriptional level.

\subsection{RNA Quadruplexes in Post-Transcriptional Regulation}

In addition to the occurrence of quadruplexes in 5 '-UTRs, in silico searches found approximately 3000 potential RNA quadruplexes within the first intron of all human RefSeq genes which show a remarkable degree of conservation [53]. Hence, RNA quadruplexes have been suspected to play a potential role in RNA processing reactions such as splicing. In addition, endonucleolytic cleavage near the 3'-end of the insulin-like growth factor II (IGF-II) mRNA has been found conserved across multiple alternatively spliced variants [54]. Interestingly, in the vicinity of this cleavage site a conserved RNA quadruplex sequence is found [55]. It was suggested that the RNA quadruplex formation may indirectly facilitate the cleavage reaction. Furthermore, dimerization of the human immunodeficiency virus type 1 (HIV-1) RNA genome during the late stage of viral replication was found to be mediated by an RNA quadruplex structure [56].

\subsection{Telomeric RNA}

Human telomeres consist of tandem 5'-GGGTTA-3' repeats and have been shown to form $\mathrm{G}$-quadruplex motifs under in vitro conditions $[57,58]$. Interestingly, due to the absence of protein-coding genes and the heterochromatin nature of the telomeric and subtelomeric regions, it was believed that telomeres are transcriptionally inactive. In particular, an $e G F P$ gene when inserted at the subtelomeric region was found to be silenced, confirming a repressive chromatin architecture [59]. However, in a recent northern blot analysis of whole-cell RNA using a telomere specific probe, a $\sim 100-9,000$ bp long telomeric repeat-containing RNA (termed TERRA) was found [60], indicating that telomeres are actively transcribed. Moreover, RNA-FISH (fluorescence in situ hybridization) experiments revealed that TERRA is co-localized with the telomere region [60]. Recently, the telomeric RNA repeat has also been shown to form an all-parallel RNA-quadruplex motif in vitro $[23,61,62]$. Although so far the non-coding TERRA has not been assigned any functional role, it is proposed to negatively regulate telomerase activity in a telomere-length-dependent manner [61], potentially by forming an RNA-DNA duplex [39]. 


\subsection{RNA Quadruplex-Interacting Proteins}

Several proteins have been identified that specifically bind and stabilize RNA quadruplexes [16]. In line, a recent study determined specific interactions of a relatively small telomeric RNA transcript, consisting of eight consecutive repeats of UUAGGG, with various telomere-associated proteins like telomere repeat factors TRF1 and TRF2, heterochromatin protein 1, histone $\mathrm{H} 3$ trimethyl $\mathrm{K} 9$, multiple subunits of origin recognition complex (ORC) and DNA-damage-sensing factors [63]. This study also showed that r(UUAGGG) $)_{8}$ can physically bind with ORC1 and TRF2 to form a ternary complex, which in turn is crucial for telomere maintenance and heterochromatin formation. The same group simultaneously showed that EpsteinBarr virus nuclear antigen 1, critical for the replication and maintenance of the Epstein-Barr virus genome, preferentially binds RNA quadruplexes and was inhibited by a G-quadruplex interacting small molecule [64]. Apart from telomere RNA-specific proteins, the coding region of fragile $\mathrm{X}$ mental retardation protein (FMRP) has been shown to fold back to form a Gquadruplex motif [65] which was found to be recognized and stabilized by FMRP itself, thereby inhibiting translation in a feedback loop [66].

In addition to the above described studies of RNA quadruplex-stabilizing proteins, an enzyme formerly characterized as an RNA helicase associated with AU-rich sequences (RHAU) was identified to specifically unwind quadruplex structures and hence termed $\mathrm{G} 4$ resolvase 1 (G4R1). It binds and resolves tetramolecular RNA quadruplexes with high affinity [67]. Moreover, competitive assays and binding affinities suggested that G4R1/RHAU resolves RNA quadruplexes more efficiently than the DNA counterparts. Especially in light of the influences of RNA quadruplexes on gene expression discussed above, the discovery of an enzymatic activity that specifically resolves such structures is an interesting finding. It is tempting to speculate whether RNA quadruplexes indeed have a distinct role as regulatory motifs or whether their presence is rather accidental with the need to dissolve such disadvantageous structures. The identification and characterization of further proteins specifically interacting with RNA quadruplexes will certainly increase our understanding of the roles and influences of these interesting higher order nucleic acid structures.

\section{CONCLUSIONS}

RNA quadruplexes are extremely stable conformations implicated in various biological processes. Recent studies illustrated regulatory potential in telomere maintenance and $\mathrm{mRNA}$ processing and translation, strongly suggesting their in vivo existence and significance. Moreover, small molecules 
stabilizing RNA quadruplexes and interfering with specific protein interactions further strengthen the importance of RNA quadruplexes. However, understanding the mechanisms that mediate in vivo formation and stability of RNA quadruplexes is very important in order to decipher the impact of these structures on cellular processes. In addition, determination of more interacting partners would augment the present repertoire of RNA quadruplex-affected processes. Targeting of specific RNA quadruplex structures and their protein interactions by small molecules may allow for controlling specific events with potential therapeutic uses. Taken together, RNA quadruplexes seem to interfere with or are involved in several RNA-associated functions. Future research along these lines will certainly gain more insight into these unusual four-stranded nucleic acid conformations.

\section{ACKNOWLEDGMENT}

KH thanks the Alexander von Humboldt-Foundation for a Fellowship, JSH acknowledges the VolkswagenStiftung and the Fonds der Chemischen Industrie for continuing support.

\section{ABBREVIATIONS}

$\begin{array}{ll}\text { A } & \text { adenine } \\ \text { bp } & \text { base pair } \\ \text { C } & \text { cytidine } \\ \text { CD } & \text { circular dichroism } \\ \text { EGFP } & \text { enhanced green fluorescent protein gene } \\ \text { FISH } & \text { fluorescence in situ hybridization } \\ \text { FMRP } & \text { fragile X mental retardation protein } \\ \text { G } & \text { guanosine } \\ \text { HIV } & \text { human immunodeficiency virus type } 1 \\ \text { IGF-II } & \text { insulin-like growth factor II } \\ \text { mRNA } & \text { messenger RNA } \\ \text { NMR } & \text { nuclear magnetic resonance } \\ \text { NRAS } & \text { neuroblastoma rat sarcoma viral oncogene } \\ \text { ORC } & \text { origin recognition complex } \\ \text { ORF } & \text { open reading frame } \\ \text { RefSeq } & \text { reference sequence } \\ \text { sSDNA } & \text { single stranded DNA } \\ \text { T } & \text { thymidine } \\ T_{1 / 2} & \text { melting temperature }\end{array}$


TRAP telomeric repeat amplification protocol

TRF telomere repeat factor

U uridine

UTR untranslated region

ZIC-1 zinc finger protein of the cerebellum 1

\section{REFERENCES}

1. M. Gellert, M. N. Lipsett and D. R. Davies, Proc. Natl. Acad. Sci. USA, 1962, 48, 2013-2018.

2. J. R. Fresco and J. Massoulie, J. Am. Chem. Soc., 1963, 85, 1352-1353.

3. Z. Du, Y. Zhao and N. Li, Genome Res., 2008, 18, 233-241.

4. P. Rawal, V. B. R. Kummarasetti, J. Ravindran, N. Kumar, K. Halder, R. Sharma, M. Mukerji, S. K. Das and S. Chowdhury, Genome Res., 2006, 16, 644655.

5. K. Halder, R. Halder and S. Chowdhury, Mol. BioSyst., 2009, 5, 1703-1712.

6. H. M. Wong and J. L. Huppert, Mol. BioSyst., 2009, 5, 1713-1719.

7. P. Mani, V. K. Yadav, S. K. Das and S. Chowdhury, PLoS One, 2009, 4, e4399.

8. N. Maizels, Nat. Struct. Mol. Biol., 2006, 13, 1055-1059.

9. A. Siddiqui-Jain, C. L. Grand, D. J. Bearss and L. H. Hurley, Proc. Nat. Acad. Sci., 2002, 99, 11593-11598.

10. K. Paeschke, T. Simonsson, J. Postberg, D. Rhodes and H. J. Lipps, Nat. Struct. Mol. Biol., 2005, 12, 847-854.

11. N. Kumar and S. Maiti, Nucleic Acids Res., 2008, 36, 5610-5622.

12. A. Risitano and K. R. Fox, Biochemistry, 2003, 42, 6507-6513.

13. D. Sen and W. Gilbert, Nature, 1988, 334, 364 366.

14. J. D. Griffith, L. Comeau, S. Rosenfield, R. M. Stansel, A. Bianchi, H. Moss and T. De Lange, Cell, 1999, 97, 503-514.

15. M. P. Horvath, V. L. Schweiker, J. M. Bevilacqua, J. A. Ruggles and S. C. Schultz, Cell, 1998, 95, 963-974.

16. M. Fry, Front. Biosci., 2007, 12, 4336-4351.

17. K. Phillips, Z. Dauter, A. I. Murchie, D. M. Lilley and B. Luisi, J. Mol. Biol, 1997, 273, 171-182.

18. A. Wlodarczyk, P. Grzybowski, A. Patkowski and A. Dobek, J. Phys. Chem. B, $2005,109,3594-3605$.

19. A. Wong and G. Wu, J. Am. Chem. Soc., 2003, 125, 13895-13905.

20. D. Miyoshi, A. Nakao, T. Toda and N. Sugimoto, FEBS Lett., 2001, 496, 128-133.

21. F. M. Chen, Biochemistry, 1992, 31, 3769-3776.

22. E. A. Venczel and D. Sen, Biochemistry, 1993, 32, 6220-6228.

23. H. Martadinata and A. T. Phan, J. Am. Chem. Soc., 2009, 131, 2570-2578.

24. A. Joachimi, A. Benz and J. S. Hartig, Bioorg. Med. Chem., 2009, 17, 6811-6815.

25. S. Kumari, A. Bugaut and S. Balasubramanian, Biochemistry, 2008, 47, 12664 12669 .

26. A. Arora and S. Maiti, J. Phys. Chem. B, 2009, 113, 10515-10520. 
27. A. Bugaut and S. Balasubramanian, Biochemistry, 2008, 47, 689-697.

28. P. Hazel, J. Huppert, S. Balasubramanian and S. Neidle, J. Am. Chem. Soc., $2004,126,16405-16415$.

29. K. Halder, M. Wieland and J. S. Hartig, Nucleic Acids Res., 2009, 37, 6811-6817.

30. M. Wieland and J. S. Hartig, Chem. Biol., 2007, 14, 757-763.

31. B. Pagano, C. A. Mattia, L. Cavallo, S. Uesugi, C. Giancola and F. Fraternali, J. Phys. Chem. B, 2008, 112, 12115-12123.

32. B. Pan, K. Shi and M. Sundaralingam, J. Mol. Biol., 2006, 363, 451-459.

33. B. Pan, Y. Xiong, K. Shi and M. Sundaralingam, Structure, 2003, 11, 1423-1430.

34. H. Liu, A. Matsugami, M. Katahira and S. Uesugi, J. Mol. Biol., 2002, 322, $955-970$.

35. D. Miyoshi, H. Karimata and N. Sugimoto, J. Am. Chem. Soc., 2006, 128, 79577963.

36. C. M. Olsen and L. A. Marky, J. Phys. Chem. B, 2009, 113, 9-11.

37. C. M. Olsen, H. T. Lee and L. A. Marky, J. Phys. Chem. B, 2009, 113, 25872595.

38. J. L. Mergny, A. De Cian, A. Ghelab, B. Sacca and L. Lacroix, Nucleic Acids Res., $2005,33,81-94$.

39. Y. Xu, K. Kaminaga and M. Komiyama, J. Am. Chem. Soc., 2008, 130, 11179 11184.

40. J. Deng, Y. Xiong and M. Sundaralingam, Proc. Natl. Acad. Sci. USA, 2001, 98, $13665-13670$.

41. J. M. Lipay and M. R. Mihailescu, Mol. Biosyst., 2009, 5, 1347-1355.

42. J. Kim, C. Cheong and P. B. Moore, Nature, 1991, 351, 331-332.

43. E. Westhof and V. Fritsch, Structure, 2000, 8, R55-65.

44. C. F. Tang and R. H. Shafer, J. Am. Chem. Soc, 2006, 128, 5966-5973.

45. G. N. Parkinson, M. P. Lee and S. Neidle, Nature, 2002, 417, 876-880.

46. J. Li, J. J. Correia, L. Wang, J. O. Trent and J. B. Chaires, Nucleic Acids Res., $2005,33,46494659$.

47. J. Qi and R. H. Shater, Nucleic Acids Res., 2005, 33, 3185-3192.

48. Y. He, R. D. Neumann and I. G. Panyutin, Nucleic Acids Res., 2004, 32, 5359m 5367.

49. N. W. Kim, M. A. Piatyszek, K. R. Prowse, C. B. Harley, M. D. West, P. L. Ho, G. M. Coviello, W. E. Wright, S. L. Weinrich and J. W. Shay, Science, 1994, 266, 2011-2015.

50. S. Kumari, A. Bugaut, J. L. Huppert and S. Balasubramanian, Nat. Chem. Biol., $2007,25,25$.

51. J. L. Huppert, A. Bugaut, S. Kumari and S. Balasubramanian, Nucleic Acids Res., 2008, 36, 6260-6268.

52. A. Arora, M. Dutkiewicz, V. Scaria, M. Hariharan, S. Maiti and J. Kurreck, $R N A, 2008,14,1290-1296$.

53. J. Eddy and N. Maizels, Nucleic Acids Res, m, 2008, 36, 1321-1333.

54. D. Meinsma, P. E. Holthuizen, J. L. Van Den Brande and J. S. Sussenbach, Biochem. Biophys. Res. Commun., 1991, 179, 1509-1516.

55. J. Christiansen, M. Kofod and F. C. Nielsen, Nucleic Acids Res., 1994, 22, 5709 5716 . 
56. W. I. Sundquist and S. Heaphy, Proc. Natl. Acad. Sci. USA, 1993, 90, 3393-3397.

57. G. Parkinson, M. Lee and S. Neidle, Nature, 2002, 417, 876-880.

58. Y. Xu, Y. Noguchi and H. Sugiyama, Bioorg. Med. Chem., 2006, 14, 5584-5591.

59. C. Koering, A. Pollice, M. Zibella, S. Bauwens, A. Puisieux, M. Brunori, C. Brun, L. Martins, L. Sabatier, J. Pulitzer and E. Gilson, EMBO Rep., 2002, 3, 1055-1061.

60. C. M. Azzalin, P. Reichenbach, L. Khoriauli, E. Giulotto and J. Lingner, Science, 2007, 318, 798-801.

61. S. Schoeftner and M. A. Blasco, Nat. Cell Biol, 2008, 10, 228-236.

62. A. Randall and J. D. Griffith, J. Biol. Chem., 2009, 284, 13980-13986.

63. Z. Deng, J. Norseen, A. Wiedmer, H. Riethman and P. M. Lieberman, Mol. Cell, $2009,35,403-413$.

64. J. Norseen, F. B. Johnson and P. M. Lieberman, J. Virol., 2009, 83, 10336-10346.

65. J. C. Darnell, K. B. Jensen, P. Jin, V. Brown, S. T. Warren and R. B. Darnell, Cell, 2001, 107, 489-499.

66. C. Schaeffer, B. Bardoni, J. L. Mandel, B. Ehresmann, C. Ehresmann and H. Moine, EMBO J., 2001, 20, 4803 4813 .

67. S. D. Creacy, E. D. Routh, F. Iwamoto, Y. Nagamine, S. A. Akman and J. P. Vaughn, J. Biol. Chem., 2008, 283, 34626-34634.

68. C. Cheong and P. B. Moore, Biochemistry, 1992, 31, 8406-8414.

69. T. Mashima, A. Matsugami, F. Nishikawa, S. Nishikawa and M. Katahira, Nucleic Acids Res., 2009, 37, 6249-6258. 